\title{
Prioritization of Black Spots in Hilly Road Segment using Road Engineering Data
}

\author{
Shubham Pandey, Gulab Singh Bura
}

\begin{abstract}
Road accidents are one of the causes of disability, injury and death. As per the latest road accident data released by the Ministry of Road Transport \& Highways (MoRTH), the total number of accidents increased by 2.5 percent from 4,89,400 in 2014 to 5,01,423 in 2015. The analysis reveals that about 1,374 accidents and 400 deaths take place every day. Every single year, it has been estimated that over three lakh persons die and 10-15 million persons are injured in road accidents throughout the world. According to the analyses, statistics of global accident indicate that in developing countries, the rate of fatality per licensed vehicle is very high as compared to that of industrialized countries. A road stretch of about 500 metres in length in which either ten fatalities or five road accidents (involving grievous injuries/fatalities) took place during last three calendar years, on National Highways is considered as a road accident black spot according to MoRTH, Government of India. In the present study the identified black spots of Haridwar and Dehradun city were included comprising of a total of 81 black spots out of which there were 49 black spots which were identified in Dehradun followed by 32 black spots in Haridwar. The present study was an attempt to carry out the prioritization of these identified blackspots with respect to the factors that were considered to evaluate accident prone locations on the road. The identified black spots were then prioritized using the classification scheme (ranking from low to high).The study reveals that the advantage of using this approach for prioritizing accident black spots on roads is that it requires very less additional data other than the road network maps.
\end{abstract}

Keywords: Black spot, Prioritization, Road Engineering, Accidents, Uttarakhand.

\section{INTRODUCTION}

$\mathrm{R}$ oad accidents have become an alarming issue across the globe. The number of serious as well as minor injuries, human sufferings and the economic loss due caused by accidents is inestimable. As per the latest road accident data released by the MoRTH, the total number of accidents increased by 2.5 percent from 4,89,400 in 2014 to 5,01,423 in 2015.

The analysis reveals that about 1,374 accidents and 400 deaths take place every day [1]. Factors like disability, injury as well as death are the major outcomes of Road accidents.

Revised Manuscript Received on February 05, 2020.

* Correspondence Author

Shubham Pandey*, Research Scholar. Department of Statistics Banasthali Vidyapith, Rajasthan, India.

E-mail : shubhambiostat@gmail.com

Gulab Singh Bura, Assistant Professor, Department of Statistics Banasthali Vidyapith, Rajasthan, India. E-mail: burastats@gmail.com

(C) The Authors. Published by Blue Eyes Intelligence Engineering and Sciences Publication (BEIESP). This is an open access article under the CC BY-NC-ND license (http://creativecommons.org/licenses/by-nc-nd/4.0/)
Every single year, it has been estimated that over three lakh persons die and 10-15 million persons are injured in road accidents throughout the world. Therefore it is necessary to incorporate steps which leads to the reduction of road accidents and implement necessary mitigating actions in order to reduce the severity as well as the number of accidents [2]. Rash and careless driving, drunken driving, access speeding, skidding, braking suddenly, violation of traffic rule, sudden twisting and turning while driving are the main causes of road accidents which ultimately leads to the major causes of morbidity and mortality worldwide, most probably in countries with low and middle income[3]. In order to have safer roads, modification and identification of black spots are essential. Moreover, for the identification of the blackspots a large number of methods have been proposed which require accident data and therefore the information is draggy to acquire. So as to achieve safe roads and to reduce the fatalities it can be very beneficiary to present a method which can identify the black spots within a short time [4]. During 2012, according to the Statistics which have been released by National Crime Records Bureau (NCRB) it has been estimated that in 4,40,042 road accidents there were 1,39,091 persons who lost their lives in India. Increase in road accidents is directly proportional to the number of vehicles [5]. As a result of growing population as well as the rapid growth of technology and economics has lead to the increase in the number of motor vehicles. The increase in mobility ultimately leads to the increase in probability of the accidents. Vehicles, the geometry of the road, the condition of the road, environmental factors etc. are the basic elements playing a major role in case of road accidents. In developing countries, the rate of fatality is more as compared to that of developed countries [6]. The identification of Black spots, according to several studies [7]-8] aims at identifying the locations in a transportation system that have difficulties and the effects of these locations can be evaluated through its crash frequency related to other similar locations. However, in order to minimize false positive and negative for a preferable reallocation of the budgets of safety investments, a method for evaluating the type of different black spot Identification shall be considered. Another crucial issue was the segmentation of roads for many researchers especially for the ones applying for screening techniques.

Road accidents: Road accidents are random in nature and can be measured by the number of persons killed and injured due to road accidents, whether on the spot or within 30 days of hospitalization due to accident. This doesn't accounts for suicides involving the use of road motor vehicles [9].

Published By: 
Blackspot: The term black spot is used to describe the dangerous points in the road network where accidents tends to cluster due to faulty engineering design, lack of education and poor enforcement of laws [10].

Moreover, these black spot in the road network should be located, prioritized and effectively eliminated to lower the rate of accidents at such locations. A road stretch of about 500 metres in length in which either ten fatalities or five road accidents (invoving grievous injuries/fatalities) took place during last three calendar years, on National Highways is considered as a road accident black spot according to Ministry of Road Transport \& Highways (MoRTH), Government of India [11]. Black Spot could be at sharp curve, intersection, straight road section of the road with a higher accident rate [12]. However, selection of dangerous locations is based on detailed study of causes and clustering of road accident and road Severity Index value.

\section{METHODOLOGY}

In order to carry out prioritization of the identified black spots in the regions of Haridwar and Dehradun city, the method described in the present study requires a road in a suitable form and certain specified road attributes. On the given road network, the accident black spots were identified. While carrying out the analysis incorporates the road related factors such as road geometries, which leads to accidents.

Table 1.1 Factors used in Prioritization with their weights

\begin{tabular}{|c|c|c|}
\hline Factors which affect the occurrence of accidents & Possible variations & Assigned Weights \\
\hline \multirow{5}{*}{ Road Width } & Single lane $3.75 \mathrm{~m}$ & 2 \\
\hline & Two lanes with raised kerbs, $7.5 \mathrm{~m}$ & 6 \\
\hline & Two lanes without raised kerbs, $7.0 \mathrm{~m}$ & 4 \\
\hline & Multi-lane pavements & 10 \\
\hline & Intermediate carriageway & 8 \\
\hline \multirow{5}{*}{ Road Type } & National Highway & 10 \\
\hline & State Highway & 8 \\
\hline & Major District Roads & 6 \\
\hline & Other District Roads & 4 \\
\hline & Village Roads & 2 \\
\hline \multirow{5}{*}{ Number of lanes in each direction } & 0 & 2 \\
\hline & 1 & 4 \\
\hline & 2 & 6 \\
\hline & 3 & 8 \\
\hline & 4 & 10 \\
\hline \multirow{4}{*}{ Drainage facilities provided } & Good & 10 \\
\hline & Satisfactory & 7 \\
\hline & Poor & 4 \\
\hline & No drainage & 1 \\
\hline \multirow{4}{*}{ Estimated number of vehicles/day } & $>1000$ & 10 \\
\hline & $>2500$ & 7 \\
\hline & $>5000$ & 4 \\
\hline & $<5000$ & 1 \\
\hline \multirow{5}{*}{ Type of Frequent Vehicle } & Carts & 10 \\
\hline & Bicycles & 8 \\
\hline & Two Wheelers & 6 \\
\hline & Car & 4 \\
\hline & Truck or bus & 2 \\
\hline \multirow{5}{*}{ Surface condition of the pavement } & WBM & 8 \\
\hline & Concrete & 10 \\
\hline & Surface Painted & 4 \\
\hline & Earth Roads & 2 \\
\hline & Other Bitumionous & 6 \\
\hline \multirow{2}{*}{ Provision of median barriers for channelization of the traffic } & No & 4 \\
\hline & Yes & 10 \\
\hline \multirow{2}{*}{ Presence of ribbon development near roads } & No & 10 \\
\hline & Yes & 4 \\
\hline \multirow{2}{*}{ Presence of shoulders } & No & 10 \\
\hline & Yes & 4 \\
\hline $\begin{array}{c}\text { Presence of edge obstructions like trees, advertising } \\
\text { hoardings, etc very close to the road }\end{array}$ & No & 10 \\
\hline
\end{tabular}

The following factors were considered in order to evaluate accident prone locations on the road:-
a) Width of the road
b) Road Type
c) Number of lanes
d) Facility of Drainage
e) Estimated number of vehicles per day
f) Type of Frequent vehicle

g) Surface condition of the pavement

h) Provision of median barriers to channelize traffic

i) Presence of edge obstructions, shoulders, ribbon development and median barriers

Published By:

4419 Blue Eyes Intelligence Engineering $\&$ Sciences Publication 
j) Presence of ribbon development near roads

However, in many of the developed countries the applied methods have demonstrated that it is possible to arrest or slow this growth in accidents. It is important to establish a reliable road accident database and analysis system. Indeed, it is likely that an inaccessible or unreliable database will only lead to inefficient management of road safety. The paper also describes 10-step process for managing black spot improvements following the proven accident investigation and prevention process. [13]

Prioritization of roads for accident occurrence

In order to achieve a desired result, prioritization involves assigning suitable weights to different factors. In the present study, the various factors influencing the occurrence of accidents on the roads were assigned weights on a scale ranging from 0 to 10 in such a manner that the factors which tends to increase the probability of the accidents have lower weights [14]. The various factors considered and the weights assigned with an attempt to prioritize roads for occurrence of accidents, are given in Table 1.1.

To each road link, the final weight assigned is obtained by adding all the individual weights and normalizing the value using maximum weight (in this case 110) that can be assigned.

Therefore,

Total weight $=\left(\sum\right.$ Individual Weights $) \times 100 / 110$

Thus road links with high final weight are less prone to accidents as compared to the road link with low final weight (14). Using the following classification scheme, roads for occurrence of accidents based on final weights has been classified:

\begin{tabular}{|l|c|}
\hline Accident prone level & Final Weight (\%) \\
\hline Very Low & $\mathbf{8 0}-100$ \\
\hline Low & $\mathbf{6 0}-\mathbf{8 0}$ \\
\hline Medium & $40-60$ \\
\hline High & $\mathbf{0}-40$ \\
\hline
\end{tabular}

\section{RESULT \& DISCUSSION}

A road stretch of about 500 metres in length in which either ten fatalities or five road accidents (invoving grievous injuries/fatalities) took place during last three calendar years, on National Highways is considered as a road accident black spot according to MoRTH, Government of India. The present study involves the black spots that were identified in Dehradun and Haridwar comprising of 81 black spots. Out of which there were 49 black spots which were identified in Dehradun followed by 32 black spots in Haridwar.

The road engineering data was directly observed for each and every identified blackspots of Dehradun \& Haridwar City. The various parameters were assigned weights and the prioritization of these blackspots were done on the basis of total cumulative weight as shown in Table 1.2 \& Table 1.3.

Table 1.2 shows the Prioritization Scheme for the
Accident Statistics on Identified Black Spots of Dehradun. The majority of the high risks of accident prone level were found in the identified blackspots in Shimla Bypass Chowk Patelnagar, Chhidarwala Raiwala,Sai Mandir Rajpur.there were 8 blackspot found in high prioritization level followed by the number of medium accidents prone were observed in Telapur Chowk Nayagaon. Motichur Raiwala,Near Miyawala Bridge Doiwala,Shiv Mandir Mussoorie Road. And the majority of low and very low accident prone blackspot were in Near R.T.O. office Haridwar bypass Road Rishikesh, N.I.V.H. Jakhan Rajpur and Shimla bypass Pratitpur Sahaspur, Near Kishan Nagar Chowk Chakrata Road Cantt. (22 blakspots are found low and very low prioritization level).

As in Table 1.3 shows the Prioritization Scheme for the Accident Statistics on Identified Black Spots of Haridwar. The majority of the high risk of accident prone level were found in the identified blackspots-Narsan Jhabreda tirah to whole Gurukul Sugar Mill to Libbarhri Jahanwi del, there were 5 blackspot found in high prioritization level followed by the medium risk of accident prone level were found in the identified blackspots -Padartha, Peelinadi, Gandikhata, Harilok tri Junction, ABB Chowk. And the majority of low and very accident prone blackspot -Baderi Sulfur Road, Shanidev Temple, Chidiyapur, Malakpur Chungi,Gurukul (there were 8 blakspots that were observed in low and very low prioritization level).

\section{CONCLUSION}

The present study concludes that the identified blackspots in hilly road segments with high prioritization level should be taken under consideration as the majority of the accidents were observed in these blackspots (ranked as high). The prioritization method will be helpful to the government for the implementing the policies in future as this approach focuses on identifying high risk blackspots which leads to reduce Road Traffic Accidents. As per the present study, the approach of prioritization scheme using the road engineering data serves an advantage over the other approaches which involves lack of accuracy due to the unavailable records of the road traffic accidents. The present study also suggests that the identified black spots which are ranked very low according to the prioritization level should not be considered as the blackspots in future as there were no accident observed in these areas. 
Prioritization of Black Spots in Hilly Road Segment using Road Engineering Data

Table 1.2 Prioritization Scheme for Identifying Black Spots of Dehradun district

\begin{tabular}{|c|c|c|c|}
\hline Black spot region & $\begin{array}{c}\text { Total } \\
\text { cumulative Wt }\end{array}$ & $\begin{array}{c}\text { Total Wt. after normalizing } \\
(\%)\end{array}$ & Prioritization level \\
\hline Shimla Bypass Chowk Patelnagar & 37 & 33.64 & High \\
\hline Chhidarwala Raiwala & 37 & 33.64 & High \\
\hline Sai Mandir Rajpur & 39 & 35.45 & High \\
\hline Kale ki Dhaal Haridwar Road Rishikesh & 39 & 35.45 & High \\
\hline Before Kulhaal power house mod & 41 & 37.27 & High \\
\hline Dharmawala Chowk Sahaspur & 41 & 37.27 & High \\
\hline Old Chowki Bypass Road & 43 & 39.09 & High \\
\hline Satyanarayan Temple Raiwala & 43 & 39.09 & High \\
\hline Telapur Chowk Nayagaon. & 47 & 42.73 & Medium \\
\hline Motichur Raiwala & 48 & 43.64 & Medium \\
\hline Near Miyawala BridgeDoiwala & 51 & 46.36 & Medium \\
\hline Shiv Mandir Mussoorie Road Rajpur & 53 & 48.18 & Medium \\
\hline Saraswati Vihar Chowk Bypass Road & 54 & 49.09 & Medium \\
\hline Ambadi mod Daakpathar Vikashnagr & 55 & 50.00 & Medium \\
\hline Kali Mandir Dehradun Road Rishikesh & 56 & 50.91 & Medium \\
\hline Langha Road Tri Junction Sahaspur & 56 & 50.91 & Medium \\
\hline Amitabh Textile Mill Chakrata Road & 56 & 50.91 & Medium \\
\hline MothroWala Chowk Bypass Road & 50 & 45.45 & Medium \\
\hline Maggi Point Rajpur & 52 & 47.27 & Medium \\
\hline D.I.T. Mussoorie Road Rajpur & 52 & 47.27 & Medium \\
\hline Near Bhardwaj Clinic Haridwar Road Rishikesh & 56 & 50.91 & Medium \\
\hline Near Kaflani Mussoorie. & 54 & 49.09 & Medium \\
\hline Bypass Road Hotel Solitaires Nehru Colony & 54 & 49.09 & Medium \\
\hline Near Harbatpur Mazar Vikashnagar & 58 & 52.73 & Medium \\
\hline Opposite Law College & 56 & 50.91 & Medium \\
\hline $\begin{array}{c}\text { Near Harrawala Police Chowki, Laxman Siddha Temple mod } \\
\text { Doiwala }\end{array}$ & 60 & 54.55 & Medium \\
\hline Near R.T.O. office Haridwar bypass Road Rishikesh & 68 & 61.82 & Low \\
\hline N.I.V.H. Jakhan Rajpur & 70 & 63.64 & Low \\
\hline I.T. Park Sahastrdhara Rajpur & 66 & 60.00 & Low \\
\hline Near Shani Mandir Chakrata Road & 68 & 61.82 & Low \\
\hline Charba Road Tri Junction Sahaspur & 74 & 67.27 & Low \\
\hline Yamuna Pul mod Badwala & 66 & 60.00 & Low \\
\hline Ranghnwala Chungi Near I.M.A. & 74 & 67.27 & Low \\
\hline Khand Village Pulia Raiwala & 78 & 70.91 & Low \\
\hline St.Jude Chowk & 74 & 67.27 & Low \\
\hline Ratanpur Chowk mod Nayagaon & 76 & 69.09 & Low \\
\hline Anahajare Chowk Patel Nagar & 71 & 64.55 & Low \\
\hline Saat Mod Dehradun Road Rishikesh & 88 & 80.00 & Very low \\
\hline Shimla bypass Pratitpur Sahaspur & 90 & 81.82 & Very low \\
\hline Near Kishan Nagar Chowk Chakrata Road Cantt. & 88 & 80.00 & Very low \\
\hline Chadni Chowk Nayagaon. & 90 & 81.82 & Very low \\
\hline Near Wood Stark School & 90 & 81.82 & Very low \\
\hline Before Maharani Suvakholi Mussoorie. & 88 & 80.00 & Very low \\
\hline Bright angle School line Jiwangarh & 90 & 81.82 & Very low \\
\hline Near Lehman bridge mod both sides. & 92 & 83.64 & Very low \\
\hline Pir Baba mod Dehari Chowk Premnagar & 102 & 92.73 & Very low \\
\hline Near Vanbeat Chowki . kunwawala & 89 & 80.91 & Very low \\
\hline Fatehpur Chowk Haridwar road Laltapad & 81 & 73.64 & Very low \\
\hline Near PNB Bank Haridwar main road Laltapad & 94 & 85.45 & Very low \\
\hline
\end{tabular}

Table 1.3 Prioritization Scheme for Identifying Black Spots of Haridwar district

\begin{tabular}{|c|c|c|c|}
\hline Black spot region & Total cumulative Wt & $\begin{array}{c}\text { Total Wt. after } \\
\text { normalizing (\%) }\end{array}$ & Prioritization level \\
\hline Narsan Jhabreda tirah to whole Gurukul & 38 & 34.55 & High \\
\hline Sugar Mill to Libbarhri & 43 & 39.09 & High \\
\hline Jahanwi del & 43 & 39.09 & High \\
\hline Rashiyabad & 37 & 33.64 & High \\
\hline Rampur Chungi & 44 & 40.00 & High \\
\hline Padartha & 47 & 42.73 & Medium \\
\hline Peelinadi & 45 & 40.91 & Medium \\
\hline Gandikhata & 47 & 42.73 & Medium \\
\hline Harilok tri Junction & 48 & 43.64 & Medium \\
\hline ABB Chowk & 45 & 40.91 & Medium \\
\hline Bongla Bypass & 46 & 41.82 & Medium \\
\hline
\end{tabular}




\begin{tabular}{|c|c|c|c|}
\hline Ranipur Jhaal & 47 & 42.73 & Medium \\
\hline SankaraCharya Chowk & 49 & 44.55 & Medium \\
\hline Chandi Chowk & 52 & 47.27 & Medium \\
\hline Shikariwala pir to Deepshikha & 57 & 51.82 & Medium \\
\hline Karoundi & 57 & 51.82 & Medium \\
\hline Daulatpur & 59 & 53.64 & Medium \\
\hline Double Fatak over bridge Mohanpura & 62 & 56.36 & Medium \\
\hline Shantikunj Gate & 67 & 60.91 & Medium \\
\hline Militry Chowk & 65 & 59.09 & Medium \\
\hline Puhana & 65 & 59.09 & Medium \\
\hline Devband thirah to Kasba Market & 65 & 59.09 & Medium \\
\hline Dudhadhari & 67 & 60.91 & Medium \\
\hline Singhdwar & 64 & 58.18 & Medium \\
\hline Baderi Sulfur Road & 69 & 62.73 & Low \\
\hline Shani dev Temple & 71 & 64.55 & Low \\
\hline Chidiyapur & 74 & 67.27 & Low \\
\hline Malakpur Chungi & 84 & 76.36 & Low \\
\hline Gurukul & 91 & 82.73 & Very low \\
\hline Mandawar & 90 & 81.82 & Very low \\
\hline Tricha pul & 94 & 85.45 & Very low \\
\hline Birla Factory to shani dev mandir & 90 & 81.82 & Very low \\
\hline
\end{tabular}

\section{REFERENCES}

1. National Crime Records Bureau (NCRB), Road Accidents in India Report, G. O. IMinistry of Road Transport \& Highways Transport Research Wing, New Delhi, 2015.

2. B. Chris, McDonald Mike, et al, "Towards Safer Roads in Developing Countries, A Guide for Planners and Engineers", Transport Research Laboratory, pp. 1-60, 1994.

3. C. Nkwonta, "Causes of Road Traffic Crashes and Prevention" in Fleet Management in Nigeria:Road Safety Perspectives, $1^{\text {st }}$ ed. Nigeria, April, 2010. ISBN - 13978 - 978 - 482-71 - 2 - 6.

4. M. Keymanesh, H. Ziari, et al. "Identification and Prioritization of (Black Spots) without Using Accident Information" , Modelling and simultation in Engineering, Article ID 1832654,2017.

5. National Crime Records Bureau (2012). “Accidental Deaths \& Suicides in India 2012," New Delhi.

6. Rakesh Kumar and A kumar (2015)." Identification and Improvement of Accident Black Spots on NH-3, Distt. Una (Himachal Pradesh) - A Case Study" department of civil engineering lovely professional university phagwara, punjab (India) - 144402

7. W. Cheng, S. P. Washington, "Experimental Evaluation of Black Spot Identification Methods", Accident Analysis \& Prevention. 37, pp. 870-881, 2005.

8. Elvik, R., "The predictive validity of empirical Bayes estimates of road safety" Accident Analysis \& Prevention 40, 1964-1969, 2008

9. https://data.oecd.org/transport/road-accidents.htm, accessed on 13 January 2017

10. N. Jain \& B. B. Jindal, "Analysis of Causal Factors of Accidents near Mahipalpur Junction on NH-8 in Delhi,"IOSR Journal of Mechanical and Civil Engineering (IOSR-JMCE), pp. 16 - 21, 2016.

11. National Transporation Planning and Research Centre-Report, "Identification and Prioritization of Accident Black Spots in Kerala," 2016.

12. P. V. Ashokbhai \& A. M. Jain, "Road Safety Audit: an Identification of Black Spots on Busy Corridor Between Narol- Naroda of Ahmedabad City," International Journal of Engineering and Technical Research,Vol 2,Issue. 3, pp. 86-89, 2014.

13. B. Chris, "Road Safety Management of theHighway Network," Int Symp. Traffic Safty Strengthening , Accident Analysis \& Prevention, 2012.

14. D. Mandloi \& R. Gupta." Evaluation of accident black spots on roads using Geographical InformationSystems (GIS)" Civil Engineering Group, BITS Pilani. January 2003.

\section{AUTHORS PROFILE}

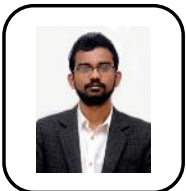

Shubham Pandey, M.Sc. (Health Statistics)-IMS, BHU

Research Scholar, Department of Statistics, Banasthali

Vidyapith, Jaipur, Rajasthan.
Published By:

Dr. Gulab Singh Bura, Assistant Professor, Department of Statistics, Banasthali Vidyapith, Jaipur, Rajasthan 